\title{
Reduction of hexavalent chromium at a polypyrrole-coated aluminium electrode: Synergistic interactions
}

\author{
KENNETH G. CONROY and CARMEL B. BRESLIN* \\ Department of Chemistry, National University of Ireland Maynooth, Maynooth, Co. Kildare, Ireland \\ (*author for correspondence, e-mail: cb.breslin@may.ie)
}

Received 4 July 2002; accepted in revised form 19 August 2003

Key words: aluminium, electropolymerization, hexavalent chromium, kinetics, pollution control, polypyrrole

\begin{abstract}
Adherent polypyrrole films were electropolymerized from a tosylic acid solution onto an aluminium substrate and used for the reduction of $\mathrm{Cr}(\mathrm{VI})$. The reduction of $\mathrm{Cr}(\mathrm{VI})$ to the trivalent state was found to proceed by pseudofirst-order kinetics with an activation energy barrier of $15.13 \mathrm{~kJ} \mathrm{~mol}^{-1}$. This catalyst could be regenerated by reducing the composite at a sufficiently negative potential, in the absence of $\mathrm{Cr}(\mathrm{VI})$. However, it was found that the catalyst functioned also through a self-sustained regeneration mechanism. In this mechanism, Cr(VI) was reduced by $\mathrm{PPy}^{0}$ to generate $\mathrm{PPy}^{+}$, but the $\mathrm{PPy}^{+}$was subsequently reduced to $\mathrm{PPy}^{0}$ by oxidation of the aluminium substrate, thus regeneration of the catalytic $\mathrm{PPy}^{0}$ surface giving rise to a synergistic action between the polypyrrole and the aluminium substrate.
\end{abstract}

\section{Introduction}

Chromium is found in group-six of the periodic table and has the ability to form stable complexes in a range of oxidation states from -2 to 6 . Of these $\mathrm{Cr}$ (III) and $\mathrm{Cr}(\mathrm{VI})$ are the most common, with the hexavalent form being toxic, carcinogenic and extremely mobile [1]. Nevertheless, hexavalent chromium is generated in a number of processes, such as leather tanning, corrosion inhibition and chrome plating. Consequently, there is an ever-increasing interest in developing procedures for the removal of toxic hexavalent chromium from the environment. Many of these procedures rely on the reduction of hexavalent chromium to the trivalent state, which is much less toxic and can be easily absorbed at a variety of inorganic and organic materials at neutral $\mathrm{pH}$ [2]. Furthermore, the trivalent chromium can be isolated as insoluble $\mathrm{Cr}$ (III) hydroxides by adjusting the $\mathrm{pH}$ to sufficiently high values, enabling the removal of chromium from the environment. Many of the current chemical [3, 4] and electrochemical treatment [5, 6] strategies rely on this reduction step. For example, in the chemical treatments, reducing agents are employed while in the electrochemical treatments direct reduction, to the trivalent state, is achieved through the application of suitable electrode potentials.

More recently, it has been shown that conducting polypyrrole films can be used to reduce $\mathrm{Cr}(\mathrm{VI})$, opening up the possibility of a new remediation-control technology [7-12]. Polypyrrole (PPy) is a well-known conducting polymer and can undergo good reversibility between its conducting and insulating states. During reduction, anionic sites are formed that require cations for charge compensation (or anion expulsion) while upon oxidation, cationic sites such as polarons $\left(\mathrm{PPy}^{+}\right)$ and bipolarons $\left(\mathrm{PPy}^{2+}\right)$, are formed on the polypyrrole chains.

The first report of the reduction of hexavalent chromium at a conducting polymer matrix was made in 1993 by Rajeshwar and co-workers [7-9] who observed the reduction of hexavalent chromium at a polypyrrole electrode, with approximately $100 \%$ efficiency, and at time intervals spanning only minutes. Furthermore, the reversibility of the polymer redox process enabled the electrochemical recycling of the polypyrrole for repeated treatment of $\mathrm{Cr}(\mathrm{VI})$. Since that time other studies have been reported on the use of polypyrrole in the reduction of $\mathrm{Cr}(\mathrm{VI})$ [10-12]. In each of these studies, inert substrates have been chosen in the preparation of the polypyrrole electrodes and there have been no reports on the participation of the substrate in the $\mathrm{Cr}(\mathrm{VI})$ reduction reaction.

In this paper a substrate with a high driving force for oxidation is chosen. Pyrrole was electropolymerized at a pure aluminium substrate to generate a polypyrrolecoated aluminium electrode. This composite was then employed in the reduction of hexavalent chromium to the less toxic trivalent state. The electrosynthesized polypyrrole coating was first reduced and then exposed to the hexavalent solution and the reduction of the hexavalent chromium monitored as a function of the exposure period. 


\section{Experimental}

Prior to electropolymerization, the samples, $99.9999 \%$ aluminium, were polished to a smooth surface finish, using successively finer grades of $\mathrm{SiC}$ paper, rinsed and dried in an air stream. In all tests, aluminium samples, with a surface area of $0.785 \mathrm{~cm}^{2}$, were used.

The PPy films were grown potentiostatically at $1.25 \mathrm{~V}(\mathrm{SCE})$ on the aluminium electrodes from aqueous

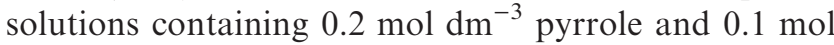
$\mathrm{dm}^{-3}$ tosylic acid in a three-electrode cell. An EG\&G potentiostat Model 263 or a Solartron EI 1287 electrochemical interface was used as the potentiostat. A saturated calomel electrode was used as reference and high-density graphite rods were employed as the counter electrode. After growth, the films were rinsed with distilled water and then reduced in $0.1 \mathrm{~mol} \mathrm{dm}^{-3}$ sulphuric acid at $-0.945 \mathrm{~V}(\mathrm{SCE})$ for a period of $30 \mathrm{~min}$. This was to ensure that the polymer was in its reduced state. The films were then washed and transferred to an acidified $\mathrm{Cr}(\mathrm{VI})$ solution $\left(15.0 \mathrm{~cm}^{3}\right.$, with a concentration range of $3.5 \times 10^{-5}$ to $6.7 \times 10^{-3} \mathrm{~mol} \mathrm{dm}^{-3}$ in $\mathrm{Cr}(\mathrm{VI})$ in $\left.0.1 \mathrm{~mol} \mathrm{dm}^{-3} \mathrm{H}_{2} \mathrm{SO}_{4}\right)$ and the concentration of $\mathrm{Cr}(\mathrm{VI})$ was monitored under open circuit potential conditions.

Reduction of the hexavalent chromium was monitored using a spectrophotometric technique. Samples were withdrawn at regular time intervals and the UVVis absorption spectra, between 200 and $800 \mathrm{~nm}$, were measured using a Cary $50 \mathrm{UV}$-Vis spectrometer. The concentration of $\mathrm{Cr}(\mathrm{VI})$ was calculated from the intense $\mathrm{Cr}(\mathrm{VI})$ charge transfer band at $350 \mathrm{~nm}$.

The electrochemical behaviour of the polypyrrolecoated aluminium samples was studied prior to and following the $\mathrm{Cr}(\mathrm{VI})$ reduction process using cyclic voltammetry. Voltammograms were recorded between -200 and $800 \mathrm{mV}(\mathrm{SCE})$ at $50 \mathrm{mV} \mathrm{s}^{-1}$.

\section{Results and discussion}

A typical plot depicting the growth of polypyrrole on pure aluminium is shown in Figure 1. For comparative purposes, the oxidation of pure aluminium in a pyrrolefree tosylic acid solution is also shown. In the absence of pyrrole, the current-time transient is characterized by a rapid decrease in the current during the first $50 \mathrm{~s}$ and then a more gradual decrease in current as the electrode is passivated in the acid solution. In contrast, the current-time behaviour is very different in the presence of pyrrole. The current initially decreases sharply, but then increases to reach a peak value of $6.0 \mathrm{~mA}$ before decaying to a near steady-state value. This behaviour is consistent with the initial oxidation of the pyrrole monomer and the nucleation and growth of the polymer film in agreement with previous studies where polypyrrole has been formed electrochemically at an aluminium substrate $[13,14]$. This procedure gave rise to adherent and smooth polypyrrole deposits that could only be removed on mechanical polishing. The thickness of the

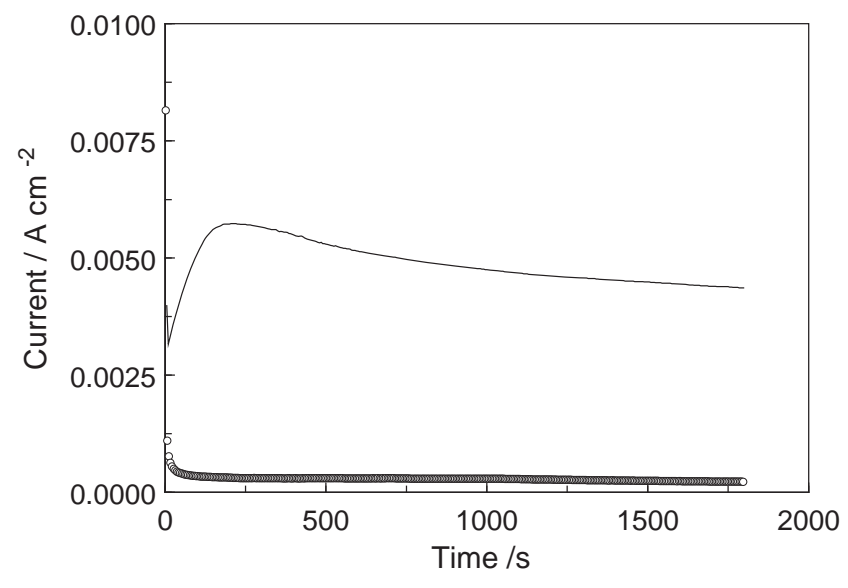

Fig. 1. Current-time transients recorded for $\mathrm{Al}$ polarized at $1.25 \mathrm{~V}(\mathrm{SCE}) \bigcirc$ in a $0.1 \mathrm{~mol} \mathrm{dm}^{-3}$ tosylic acid solution and - in $0.1 \mathrm{~mol} \mathrm{dm}^{-3}$ tosylic acid and $0.3 \mathrm{~mol} \mathrm{dm}^{-3}$ pyrrole.

polypyrrole coating was estimated as $17-18 \mu \mathrm{m}$, using the relationship that $600 \mathrm{mC} \mathrm{cm}^{-2}$ corresponds to a $1.0 \mu \mathrm{m}$ thick polypyrrole film [15].

Following formation of the polymer at the aluminium electrode, the polymer was reduced in the sulphuric acid solution in accordance with Equation 1.

$$
\mathrm{PPy}_{(\mathrm{s})}^{+}+\mathrm{e}^{-} \rightarrow \mathrm{PPy}_{(\mathrm{s})}^{0}
$$

Here, the 0 and + superscripts correspond to the reduced and oxidized states of the polypyrrole respectively. This reduced polymer-coated electrode was then immersed in acidified solutions of varying dichromate concentration. These acidic conditions were employed as it is well known that the reduction of $\mathrm{Cr}(\mathrm{VI})$ proceeds more efficiently under acidic conditions, and indeed this has been observed with polypyrrole-coated carbon electrodes [9]. Typical UV-visible spectra showing the uptake and reduction of $\mathrm{Cr}(\mathrm{VI})$ during contact with the polymer-modified electrode are shown in Figure 2. The charge transfer band centred at $350 \mathrm{~nm}$ for the $\mathrm{Cr}_{2} \mathrm{O}_{7}^{2-}$

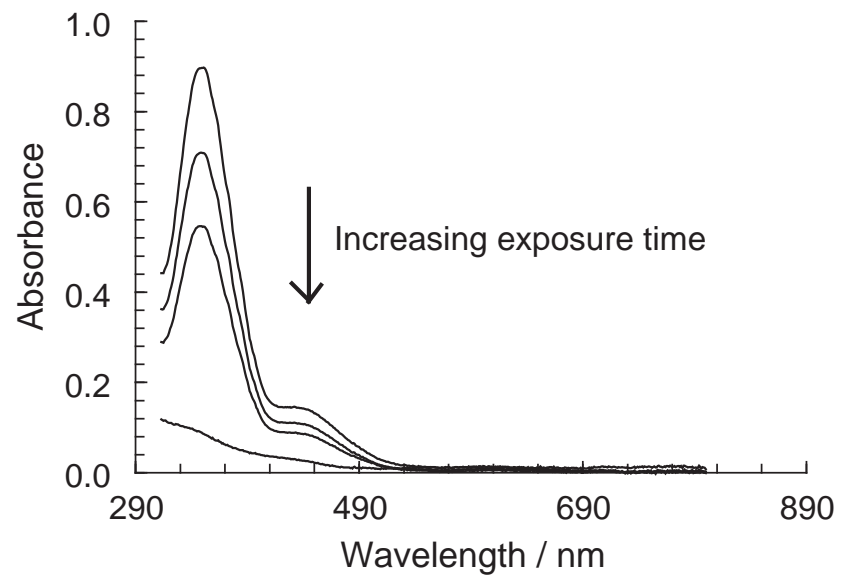

Fig. 2. UV-visible spectra recorded for an acidified $\mathrm{Cr}(\mathrm{VI})$ solution as a function of the exposure time to the polypyrrole-coated electrode. Data were recorded at time intervals of $0,275,350$ and $600 \mathrm{~min}$. 
complex can be seen clearly. It is also clear that the absorbance decreases with increasing exposure time. These data were recorded in a $1.34 \times 10^{-3} \mathrm{~mol} \mathrm{dm}^{-3}$ $\mathrm{Cr}$ (VI) solution at $0,275,350$ and $600 \mathrm{~min}$ and it can be seen that the absorbance decreases considerably between these time intervals. At lower $\mathrm{Cr}(\mathrm{VI})$ concentrations (for example $1.66 \times 10^{-4} \mathrm{~mol} \mathrm{dm}^{-3}$ ) complete disappearance of the dichromate band was observed following $100 \mathrm{~min}$; this was accompanied by a gradual change in the colour of the dichromate solution from orange-like to almost colourless. This removal of $\mathrm{Cr}(\mathrm{VI})$ is consistent with the reduction of the hexavalent chromium to the stable trivalent state with the resultant oxidation of the polymer in accordance with Equation 2.

$$
\begin{aligned}
& \mathrm{Cr}_{2} \mathrm{O}_{7(\mathrm{aq})}^{2-}+14 \mathrm{H}^{+}+6 \mathrm{PPy}_{(\mathrm{s})}^{0} \\
& \quad \rightarrow 2 \mathrm{Cr}_{(\mathrm{aq})}^{3+}+6 \mathrm{PPy}_{(\mathrm{s})}^{+}+7 \mathrm{H}_{2} \mathrm{O}_{(\mathrm{l})}
\end{aligned}
$$

Indeed, it was possible to detect the Cr(III) complex, by recording the UV-visible spectrum of a $6.7 \times 10^{-3}$ mol $\mathrm{dm}^{-3} \mathrm{Cr}(\mathrm{VI})$ solution exposed to a polypyrrolecoated electrode for a period exceeding $800 \mathrm{~min}$. This shows that the reduced $\mathrm{Cr}$ (III) is released into the solution environment, and although some may be trapped within the polymer, large amounts of $\mathrm{Cr}$ (III) are released into the solution phase.

This reduction process was found to obey pseudofirst-order kinetics. This is in agreement with reports in the literature, in which $\mathrm{Cr}(\mathrm{VI})$ has been reduced at a polypyrrole-coated carbon substrate [9, 12], reduced by hydrogen peroxide [16], reduced by iron [17] and reduced by hydrogen sulphide [18]. The rate law, for the dichromate reduction reaction, may be expressed as Equation 3.

$$
R=k[\mathrm{Cr}(\mathrm{VI})]^{1}\left[\mathrm{PPy}^{0}\right]^{\mathrm{m}}\left[\mathrm{H}^{+}\right]^{\mathrm{p}}
$$

However, since the acid is in excess $\left(0.1 \mathrm{~mol} \mathrm{dm}^{-3}\right)$ and assuming that the concentration of $\mathrm{PPy}^{0}$ remains high and is invariant relative to the levels of $\mathrm{Cr}(\mathrm{VI})$, then Equation 3 may be reduced to Equation 4 where $k^{1}$ represents a pseudo-first-order rate constant.

$$
R=k^{1}[\mathrm{Cr}(\mathrm{VI})]^{1}
$$

A typical pseudo-first-order plot showing the logarithm of the $\mathrm{Cr}(\mathrm{VI})$ concentration as a function of time is shown in Figure 3. This reasonable adherence to pseudo-first-order kinetics indicates that the concentration of $\mathrm{PPy}^{0}$ remains essentially constant throughout the duration of the experiments. The pseudo-first-order rate constant $\left(k^{1}\right)$ was found to be $2.3 \times 10^{-3} \mathrm{~min}^{-1}$. Although this low value is indicative of a slow reaction, it is partly connected, also, with the low surface area of the polymer exposed to the solution $\left(0.785 \mathrm{~cm}^{2}\right)$, as the reduction of $\mathrm{Cr}(\mathrm{VI})$ is a surface phenomenon. Indeed, Wampler et al. [19] have shown that the $\operatorname{Cr}(\mathrm{VI})$ conversion is best expressed per unit geometric surface of the sample.

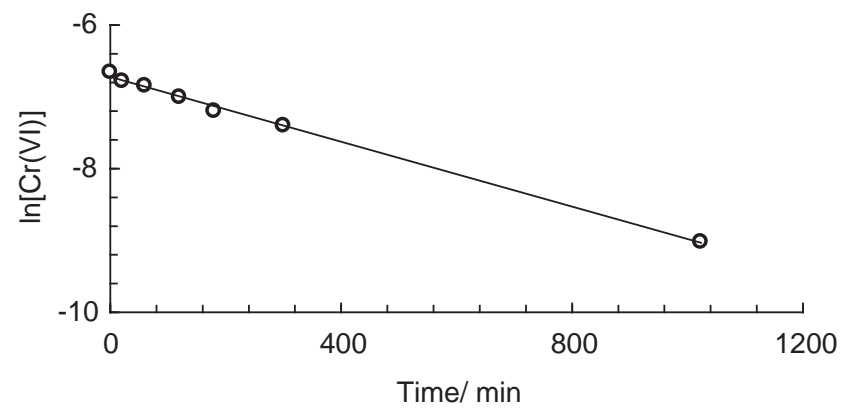

Fig. 3. First-order kinetics plot showing the logarithm of the concentration of $\mathrm{Cr}(\mathrm{VI})$ plotted as a function of time.

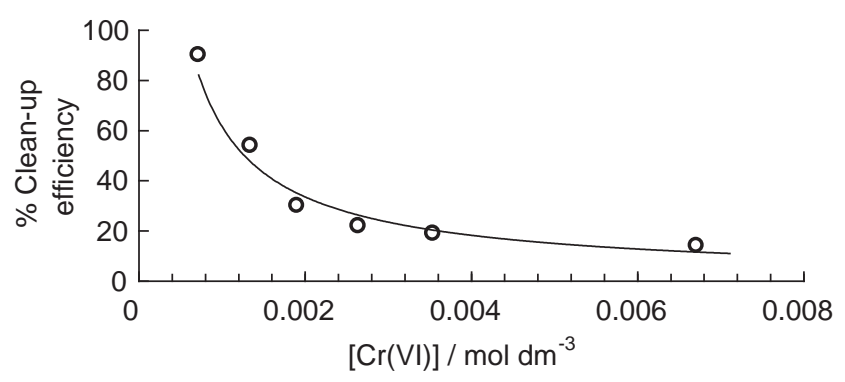

Fig. 4. Clean-up efficiency, expressed as a $\%$ of the initial concentration and calculated following a $180 \mathrm{~min}$ exposure period, plotted as a function of the initial concentration of $\mathrm{Cr}(\mathrm{VI})$.

Using various initial concentrations of $\mathrm{Cr}(\mathrm{VI})$, the rate of reduction was monitored as a function of temperature. Using the Arrhenius equation, the activation energy was computed as $15.13 \mathrm{~kJ} \mathrm{~mol}^{-1}$. Again, this represents a relatively high value for the activation energy.

Data showing the clean-up efficiency of the polypyrrole-modified Al electrode, measured over a 180-min exposure period, are shown in Figure 4. Near to $100 \%$ reduction efficiencies occur with the more dilute $\mathrm{Cr}(\mathrm{VI})$ solutions, but the efficiencies are much lower, for these short periods, with the more concentrated solutions. However, even with these more concentrated solutions, for example, $6.7 \times 10^{-3} \mathrm{~mol} \mathrm{dm}^{-3} \mathrm{Cr}(\mathrm{VI})$, complete reduction i.e. $100 \%$ reduction efficiency was observed after $830 \mathrm{~min}$ of exposure. These findings are consistent with a slow but continued uptake and reduction of $\mathrm{Cr}(\mathrm{VI})$, and are indicative of a regeneration process or mechanism. Clear evidence in support of this was obtained by calculating the theoretical number of $\mathrm{PPy}^{0}$ sites and assuming a $100 \%$ reduction efficiency, the maximum amount of $\mathrm{Cr}(\mathrm{VI})$ that should be reduced. For example in a typical reaction, for instance the $1.342 \times 10^{-3} \mathrm{~mol} \mathrm{dm}^{-3} \mathrm{Cr}(\mathrm{VI})$ solution $\left(15 \mathrm{~cm}^{3}\right)$, the number of $\mathrm{PPy}^{+}$sites was calculated as $4.15 \times 10^{-5} \mathrm{~mol}$ of PPy units using Faraday's law and the electrosynthesis charge. Assuming a doping level of 0.3 (i.e. one positive charge per three rings [19]) then the number of trimers can be computed as $1.38 \times 10^{-5} \mathrm{~mol}$. Since a trimer is involved in the redox reaction $\mathrm{PPy}^{0} \rightarrow$ $\mathrm{PPy}^{+}+\mathrm{e}^{-}$, then the number of $\mathrm{PPy}^{+}$sites is also equal 


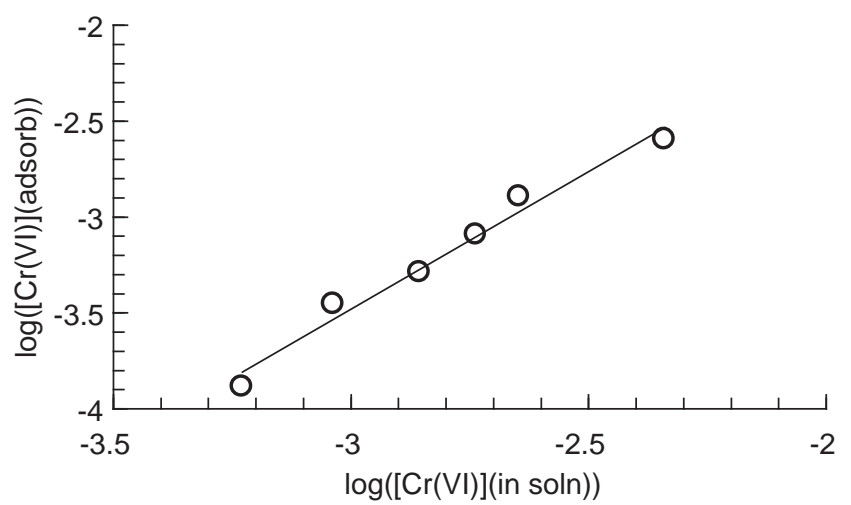

Fig. 5. Freundlich isotherm plot showing the logarithmic dependence between the concentrations of the adsorbed $\mathrm{Cr}(\mathrm{VI})$ and $\mathrm{Cr}(\mathrm{VI})$ in solution.

to $1.38 \times 10^{-5} \mathrm{~mol}$. Assuming $100 \%$ reduction efficiency and using a stoichiometric ratio of $3 \mathrm{PPy}^{0}$ to $1 \mathrm{Cr}^{6+}$, then the theoretical amount of $\mathrm{Cr}^{6+}$ removed should be $23 \%$. However, the actual amount of $\mathrm{Cr}^{6+}$ removed was $94 \%$ following a $300 \mathrm{~min}$ immersion period. Indeed, this will approach $100 \%$ if exposed for an additional time period. This large discrepancy between the theoretical and actual amounts lies well outside any possible error in the estimation of the film thickness and the number of $\mathrm{PPy}^{+}$sites. Consequently, the reduction of $\mathrm{Cr}(\mathrm{VI})$ must also proceed by another additional route or through a regeneration mechanism.

Further evidence in support of such a regeneration mechanism was obtained by fitting the $\mathrm{Cr}(\mathrm{VI})$ reduction data for the polypyrrole-coated electrode to the Freundlich isotherm. This is shown by the linear dependence between the logarithm of the concentration of the adsorbed $\mathrm{Cr}(\mathrm{VI})$ and the logarithm of the concentration of the free $\mathrm{Cr}(\mathrm{VI})$ in solution, as presented in Figure 5. This isotherm, for adsorption from solution, can be represented by the relationship,

$$
\frac{x}{m}=k c^{1 / n}
$$

where $k$ and $n$ are empirical constants, with the value of $n$ usually less than unity, $x$ represents the amount of solute adsorbed by mass $m$ of solid, while $c$ represents the concentration of the solute species in solution. Assuming that $\mathrm{Cr}(\mathrm{VI})$ is first adsorbed prior to reduction, then $x$ can be equated with the concentration of reduced $\mathrm{Cr}(\mathrm{VI})$, while $c$ corresponds to the original concentration of $\mathrm{Cr}(\mathrm{VI})$ in solution. In these experiments the initial concentration of $\mathrm{Cr}(\mathrm{VI})$ was varied. The concentration of $\mathrm{Cr}(\mathrm{VI})$ remaining in solution following a $120 \mathrm{~min}$ immersion period was then determined and equated with $x$. This isotherm is based on the principle that saturation of the surface does not occur, i.e. the amount adsorbed increases with increasing concentration, suggesting that the $\mathrm{PPy}^{0}$ sites are in excess during these reduction experiments. Given the relatively small surface area used in these experiments

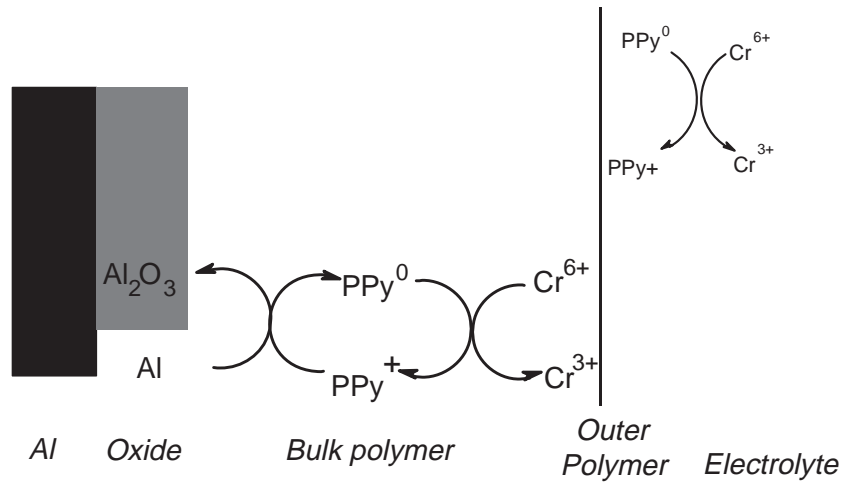

Fig. 6. Schematic plot depicting the reactions, which occur in the regeneration mechanism.

coupled with the relatively high $\mathrm{Cr}(\mathrm{VI})$ concentrations, then saturation of the $\mathrm{PPy}^{0}$ surface should be achieved easily unless the surface is regenerated enabling further adsorption and reduction.

This regeneration, or synergistic, mechanism can be represented by the diagram depicted in Figure 6. At the polymer-solution interface direct electron transfer between the $\mathrm{PPy}^{0}$ and $\mathrm{Cr}(\mathrm{VI})$ occurs resulting in reduction of the hexavalent chromium to the trivalent state. However, the oxidized polypyrrole in contact with the aluminium substrate generates a galvanic couple enabling the regeneration of the reduced polypyrrole in accordance with Equation 6.

$$
\mathrm{Al}+3 \mathrm{PPy}^{+} \rightarrow \mathrm{Al}^{3+}+3 \mathrm{PPy}^{0}
$$

This represents a thermodynamically feasible reaction with a free energy of $-490.63 \mathrm{~kJ} \mathrm{~mol}^{-1}$ (computed from the standard reduction potentials of the $\mathrm{Al} \mid \mathrm{Al}^{3+}$ and $\mathrm{PPy}^{0} \mid \mathrm{PPy}^{+}$couples). This aluminium oxidation half reaction gives rise to the production of aluminium oxide or hydrated aluminium oxide as shown in the diagram. Indeed, evidence for the participation of this reaction for the polypyrrole-coated electrode could be seen on removing the polypyrrole coating from the aluminium substrate following extended immersion in the $\mathrm{Cr}(\mathrm{VI})$ solution. A thick white layer could be observed on the aluminium, which is consistent with an aluminium oxide layer, $\mathrm{Al}_{2} \mathrm{O}_{3}$, with aluminium in the trivalent state. The reduction couple gives rise to the regeneration of the reduced polypyrrole, which can now participate in the reduction of the hexavalent chromium, providing a selfsustained regeneration of the catalyst. It is interesting to note that although this regeneration of the catalyst results in an increase in the thickness of the aluminium oxide layer, detachment of the polymer from the substrate does not occur, at least not for time intervals up to 35 days.

As shown in Figure 6, the $\mathrm{Cr}(\mathrm{VI})$ species may be reduced also within the outer layers of the polymer film. However, it is unlikely that the Cr(VI) species will travel to any great extent within the bulk polymer. Indeed, Senthurchelvan et al. [9] have concluded from their 


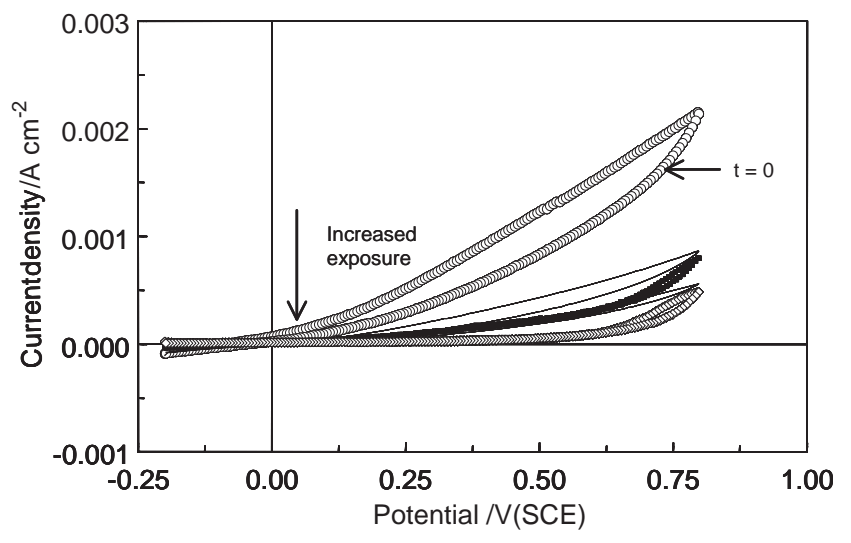

Fig. 7. Cyclic voltammograms recorded for the polypyrrole-coated aluminium electrode following exposure to $125 \mathrm{~cm}^{3}$ of a $1.3 \times 10^{-3}$ mol dm ${ }^{-3} \mathrm{Cr}(\mathrm{VI})$ solution. Data recorded following $0,1,2,33,58$ and $830 \mathrm{~h}$.

studies, on the efficiency of a polypyrrole-coated carbon catalyst, that only the external surface of the polymer is easily accessible to the $\mathrm{Cr}(\mathrm{VI})$ species. Further conversion of the $\mathrm{Cr}(\mathrm{VI})$ is limited by the penetration of $\mathrm{Cr}(\mathrm{VI})$ and the reaction zone into the bulk of the polymer.

The electrochemical activity of the polypyrrole-coated electrode as a function of the exposure period to the $\mathrm{Cr}(\mathrm{VI})$ solution is shown in Figure 7. In this figure, cyclic voltammograms are presented, recorded at $50 \mathrm{mV} \mathrm{s}^{-1}$, between the potential limits of -200 and $800 \mathrm{mV}$ (SCE). These data were recorded following 0,1 , $2,33,58$ and $830 \mathrm{~h}$ of exposure to a $1.3 \times 10^{-3} \mathrm{~mol}$ $\mathrm{dm}^{-3} \mathrm{Cr}(\mathrm{VI})$ solution. On comparison of these voltammograms, a clear reduction in the measured current can be seen between the voltammogram recorded at time $=0$ and the subsequent periods. This reduction in the anodic current may be connected with the degradation of the polymer or with the formation of aluminium oxide, giving rise to a semi-insulating interface between aluminium and the polypyrrole coating. The presence of a semi-insulating layer may impede charge transport to the outer layers. Long term immersion experiments, which involved exposing Al-PPy to a concentrated solution of $\mathrm{Cr}(\mathrm{VI})$ for over a month showed no visible signs of degradation, suggesting that the decrease in current is probably more connected with the oxidation of the aluminium substrate than degradation of the polymer.

In addition, it was possible to regenerate these composites by reducing the polypyrrole. Again, this suggests that the polymer is not degraded substantially on exposure to the highly aggressive $\mathrm{Cr}(\mathrm{VI})$ solution. Regardless of the concentration of $\mathrm{Cr}(\mathrm{VI})$, the composite was restored to $100 \%$ of its efficiency by reduction at $-945 \mathrm{mV}$ (SCE) in the $0.1 \mathrm{~mol} \mathrm{dm}{ }^{-3} \mathrm{H}_{2} \mathrm{SO}_{4}$ solution for a 30 -min period. This procedure was repeated three times; the composite was exposed to $\mathrm{Cr}(\mathrm{VI})$ for $24 \mathrm{~h}$, then reduced, exposed to a fresh solution of $\mathrm{Cr}(\mathrm{VI})$ for a further $24 \mathrm{~h}$, reduced again and finally immersed in a fresh $\mathrm{Cr}(\mathrm{VI})$ solution for a further $24 \mathrm{~h}$-period. No loss in the efficiency of the $\mathrm{Cr}(\mathrm{VI})$ reduction reaction was seen.

\section{Conclusions}

The reduction of $\mathrm{Cr}(\mathrm{VI})$ by a polypyrrole-modified aluminium electrode proceeds by pseudo-first-order kinetics with an activation energy barrier of $15.13 \mathrm{~kJ} \mathrm{~mol}^{-1}$. It was found that this catalyst functioned through a regeneration mechanism, whereby $\mathrm{Cr}(\mathrm{VI})$ was reduced by $\mathrm{PPy}^{0}$ to generate $\mathrm{PPy}^{+}$, but the $\mathrm{PPy}^{+}$was subsequently reduced to $\mathrm{PPy}^{0}$ by oxidation of the aluminium substrate, thus regeneration of the catalytic $\mathrm{PPy}^{0}$ surface.

\section{Acknowledgements}

The authors gratefully acknowledge the support of this work by Enterprise Ireland, under the Basic Science Research Grants Award, Project Code SC/99/106.

\section{References}

1. F. Katz and K. Salem, 'The Biological and Environmental Chemistry of Chromium', (VCH Publishers, New York, 1194), pp. 51-58.

2. S. Srivastava, S. Prakash and M.M. Srivastava, Biometals 12 (1999) 201.

3. J.C. Seaman, P.M. Bertsch and L. Schwallie, Environ. Sci. Technol. 33 (1999) 938.

4. T.E. Higgins, A.R. Halloran and J.C. Petura, J. Soil Contam. 6 (1997) 767.

5. N. Melitas, O. Chuffe-Moscoso and J. Farrell, Environ. Sci. Technol. 35 (2001) 3948.

6. S.A. Martinez, M.G. Rodriguez and C. Barrera, Water Sci. Technol. 42 (2000) 55.

7. C. Wei, S. German, S. Basak and K. Rajeshwar, J. Electrochem. Soc. 140 (1993) L60.

8. W.A. Wampler, K. Rajeshwar, R.G. Pethe, R.C. Hyer and S.C. Sharma, J. Mater. Res. 10 (1995) 1811.

9. R. Senthurchelvan, Y. Wang, S. Basak and K. Rajeshwar, J. Electrochem. Soc. 143 (1996) 44.

10. M.A. Alatorre, S. Gutierrez, U. Paramo and J.G. Ibanez, J. Appl. Electrochem. 28 (1998) 551.

11. E. Desimoni and I. Bassani, Anal. Commun. 36 (1999) 45.

12. F.J. Rodriguez, S. Gutierrez, J.G. Ibanez, J.L. Bravo and N. Batina, Environ. Sci. Technol. 34 (2000) 2018.

13. S.B. Saidman, J. Electroanal. Chem. 534 (2002) 39.

14. S.B. Saidman and J.B. Bessone, J. Electroanal. Chem. 521 (2002) 87.

15. H.N.T. Le, B. Garcia, C. Deslouis and Q. Le Xuan, Electrochim. Acta 46 (2001) 4259.

16. M. Pettine, L. Campanella and F.J. Millero, Environ. Sci. Technol. 36 (2002) 901.

17. M.J. Alowitz and M.M. Scherer, Environ. Sci. Technol. 36 (2002) 299.

18. C. Kim, Q.H. Zhou, B.L. Deng, E.C. Thornton and H.F. Xu, Environ. Sci. Technol. 35 (2001) 2219.

19. W.A. Wampler, S. Basak and K. Rajeshwar, Carbon 34 (1996) 747. 